\title{
Maternal and cord blood vitamin D level and the infant gut microbiota in a birth cohort study
}

\author{
Zeinab Kassem', Alexandra Sitarik1, Albert M. Levin', Susan V. Lynch², Suzanne Havstad', Kei Fujimura², \\ Anita Kozyrskyj ${ }^{3}$, Dennis R. Ownby ${ }^{4}$, Christine Cole Johnson ${ }^{1,5}$, Germaine J. M. Yong ${ }^{2}$, Ganesa Wegienka ${ }^{1,5}$ and \\ Andrea E. Cassidy-Bushrow ${ }^{1,5^{*}}$ (D)
}

\begin{abstract}
Background: Mounting evidence suggests both vitamin D and the early life gut microbiome influence childhood health outcomes. However, little is known about how these two important exposures are related. We aimed to examine associations between plasma 25-hydroxyvitamin D (25[OH]D) levels during pregnancy or at delivery (cord blood) and infant gut microbiota.

Methods: Maternal and cord blood 25[OH]D levels were assessed in a sample of pregnant women. Compositional analyses adjusted for race were run on the gut microbiota of their offspring at 1 and 6 months of age.

Results: Mean prenatal 25(OH)D level was $25.04 \pm 11.62 \mathrm{ng} / \mathrm{mL}$ and mean cord blood 25(OH)D level was $10.88 \pm$ $6.77 \mathrm{ng} / \mathrm{mL}$. Increasing prenatal 25(OH)D level was significantly associated with decreased richness $(p=0.028)$ and diversity $(p=0.012)$ of the gut microbiota at 1 month of age. Both prenatal and cord $25(\mathrm{OH}) \mathrm{D}$ were significantly associated with 1 month microbiota composition. A total of 6 operational taxonomic units (OTUs) were significantly associated with prenatal 25(OH)D level (four positively and two negatively) while 11 OTUs were significantly associated with cord 25(OH)D (10 positively and one negatively). Of these, OTU 93 (Acinetobacter) and OTU 210 (Corynebacterium), were consistently positively associated with maternal and cord 25(OH)D; OTU 64 (Ruminococcus gnavus) was positively associated with prenatal 25(OH)D but negatively associated with cord 25(OH)D.
\end{abstract}

Conclusions: Prenatal maternal and cord blood 25(OH)D levels are associated with the early life gut microbiota. Future studies are needed to understand how vitamin D and the microbiome may interact to influence child health.

Keywords: Vitamin D, Gut microbiota, Birth cohort, Cord blood

\section{Background}

Vitamin D is necessary for optimal maternal and fetal health during pregnancy [1], however, vitamin D deficiency and inadequacy is common during this time [2]. In addition to potential bone problems in offspring, maternal

\footnotetext{
* Correspondence: acassid1@hfhs.org

'Department of Public Health Sciences, Henry Ford Hospital, 1 Ford Place, 5C, Detroit, MI 48202, USA

${ }^{5}$ Center for Urban Responses to Environmental Stressors, Wayne State University, Detroit, MI, USA

Full list of author information is available at the end of the article
}

vitamin D level may impact child health outcomes, including risk for allergy/asthma and obesity [3-5]. Growing evidence suggests these child health outcomes may also be associated with the gut microbiome [6].

Vitamin D level may impact the structure and function of the gut microbiome. In vitamin D receptor knockout mice, there are significant community level and functional changes in the gut microbiota compared to wild type mice [7, 8]. Mice that cannot produce 1,25-dihydroxycholecalciferol exhibit gut microbiome dysbioisis 
[8]. There is sufficient evidence in humans that vitamin $\mathrm{D}$ level is associated with gut microbiome composition [9]. Maternal dietary vitamin D intake is also associated with maternal gut microbiome measured 4 days after delivery [10]. Only a few studies have examined potential associations between maternal vitamin $\mathrm{D}$ level and gut microbiome in early life. In the KOALA birth cohort, maternal vitamin D supplementation and maternal 25hydroxyvitamin D $(25[\mathrm{OH}] \mathrm{D})$ quintiles were negatively associated with counts of Bifidobacterium species and there was a positive association between maternal 25(OH)D quintiles and B. fragilis counts in 1 month old infant gut microbiota [11]. Cord blood 25(OH)D was associated with higher levels of Lachnobacterium and lower levels of Lactococcus in the Vitamin D Antenatal Asthma Reduction Trial [12]. These findings suggest maternal vitamin D levels might influence the abundance of several key bacterial taxa within the infant microbiota.

The infant gut microbiome is initially seeded by the maternal microbiome [13]; through an influence on the maternal microbiome, prenatal vitamin D level may potentially influence the infant gut microbiome. Additional study of the role of prenatal vitamin D in infant microbiome development is needed [12]. We examined if 25(OH)D levels during pregnancy (measured between 25 and 44 weeks gestation; mean $=33$ weeks) or at delivery (in cord blood) were associated with the infant gut microbiota at infant ages $\sim 1$ month and $\sim 6$ months in a sample of maternal-child pairs from the racially and socioeconomically diverse Wayne County Health, Environment, Allergy and Asthma Longitudinal Study (WHEA LS) birth cohort $[3,14]$.

\section{Methods}

\section{Study population}

WHEALS recruited pregnant women with due dates from September 2003 through December 2007, and who were seeing an obstetric practitioner at 1 of 5 clinics of an urban health system to establish a birth cohort [3, 14]. All women were in their second trimester or later, were aged 21-49 years, and were living in a predefined geographic area in Wayne and Oakland counties that included the city of Detroit as well as the suburban areas immediately surrounding the city. All participants provided written, informed consent and study protocols were approved by the Institutional Review Board at Henry Ford Health System. The original WHEALS cohort recruited 1258 mother-child pairs.

\section{Stool specimens}

Home visits with participants were conducted targeting infant ages 1 and 6 months. Families were asked to retain the most recent soiled diaper prior to the home visit and stool samples were banked at $-80^{\circ} \mathrm{C}$. Detailed information on DNA extraction methods are presented elsewhere [15].

\section{Polymerase chain reaction conditions and library preparation for sequencing}

The V4 region of the 16S rRNA gene was amplified, as described by Caporaso, Lauber [16]. Briefly, 16S rRNA amplification was performed in $25-\mu \mathrm{L}$ reactions using 0.025 U Takara Hot Start ExTaq (Takara Mirus Bio Inc., Madison, WI), 1X Takara buffer with $\mathrm{MgCl} 2,0.4 \mathrm{pmol} /$ $\mu \mathrm{L}$ of $\mathrm{F} 515$ and $\mathrm{R} 806$ primers, $0.56 \mathrm{mg} / \mathrm{mL}$ of bovine serum albumin (Roche Applied Science, Indianapolis, IN), $200 \mu \mathrm{M}$ of dNTPs and $10 \mathrm{ng}$ of genomic DNA. Reactions were performed in triplicate with the following: initial denaturation $\left(98^{\circ} \mathrm{C}, 2 \mathrm{~min}\right), 30$ cycles of $98^{\circ} \mathrm{C}(20$ $\mathrm{s})$, annealing at $50^{\circ} \mathrm{C}(30 \mathrm{~s})$, extension at $72^{\circ} \mathrm{C}(45 \mathrm{~s})$, and final extension at $72{ }^{\circ} \mathrm{C}(10 \mathrm{~min})$. Amplicons were verified using a $2 \%$ Tris/Borate/EDTA agarose e-gel (Life Technologies, Grand Island, NY), cleaned and normalized using SequalPrep Normalization Plates (Applied Biosystems, Foster City, CA), and further quantified using the Qubit 2.0 Fluorometer and the doublestranded DNA HS Assay Kit (Life Technologies). Samples were pooled in equal moles at concentrations of 5 ng, purified using AMPure SPRI beads (Beckman Coulter, Brea, CA), denatured and diluted to $2 \mathrm{nM}$, and $5 \mathrm{pM}$ was loaded onto the Illumina Nextseq cartridge with $40 \%(\mathrm{v} / \mathrm{v})$ of denatured $12.5 \mathrm{pM}$ PhiX spike-in control.

\section{Sequence data processing and quality control}

Paired-end sequences were assembled using FLASH v 1.2.7 [17], de-multiplexed by barcode, and low quality reads $(\mathrm{Q}$-score $<30)$ were discarded in QIIME 1.8 [18]. Reads were truncated if 3 consecutive bases were $<$ Q30, and were retained only if the truncated sequence was $\geq 75 \%$ of the original length. UCHIME [19] was used to check for chimeras, which were filtered from the dataset prior to operational taxonomic unit (OTU) picking at 97\% sequence identification using UCLUST [20] against the GreenGenes database version 13_5 [21]; sequence reads that failed to cluster with a reference sequence were clustered de novo. Sequences were aligned using PyNAST [22], and taxonomy assigned using the RDP classifier [23] and GreenGenes reference database version 13_5 [21]. FastTree 2.1.3 [24] was used to build a phylogenetic tree. To normalize variation in read depth across samples, data was rarefied to the minimum read depth of 60,000 sequences per sample. To ensure that a representative subsample was selected, a representative rarefying algorithm described previously was implemented [25]. 
A total of 580 children had at least 1 stool sample in the final rarefied OTU table; of these, 499 unique children (700 total stool specimens) had a maternal or cord blood $25(\mathrm{OH}) \mathrm{D}$ measurement and are included in the statistical analysis. Table 1 presents the breakdown of those with each measure (microbiota, $25[\mathrm{OH}] \mathrm{D}$ ) by each time point (1 and 6 months or prenatal and cord, respectively). In the analytical dataset, stool specimens from the 1 month visit were collected at a mean \pm standard deviation (SD) of $40 \pm 17$ days (minimum $=16$, maximum $=137$ ) and stool specimens from the 6 month visit were collected at a mean \pm SD of $207 \pm 31$ days (minimum $=168$, maximum $=322$ ). Throughout, "1 month" and " 6 month" are used as labels of the intended time period of sample collection.

\section{Vitamin D measurement}

$25(\mathrm{OH}) \mathrm{D}$ was measured in frozen $\left(-80^{\circ} \mathrm{C}\right)$ plasma samples from pregnancy (range $=25-44$ weeks gestation; mean $=33$ weeks) and delivery (cord blood) in the laboratory of Dr. Neil Binkley at the University of Wisconsin using a high-performance liquid chromatography method $[3,14,26]$. For those with $25(\mathrm{OH}) \mathrm{D}$ levels below the lowest detectable limit of $5 \mathrm{ng} / \mathrm{mL}$, a value of $2.5 \mathrm{ng} /$ $\mathrm{mL}$ was assigned $(N=11$ for prenatal and $N=81$ for cord $25[\mathrm{OH}] \mathrm{D})$. There is no overall consensus on optimal vitamin $\mathrm{D}$ levels in pregnancy; however, levels above $20 \mathrm{ng} / \mathrm{mL}$ prevent bone-related pathologies [2]. Therefore, insufficient levels of vitamin D were defined as < $20 \mathrm{ng} / \mathrm{mL}[2]$.

To account for seasonal variation in vitamin $\mathrm{D}$, as described by Wegienka, Havstad [3], we fit a sinusoidal model of the values $(25[\mathrm{OH}] \mathrm{D}$ value) and time (month, denoted as "m") of collection:

$$
\begin{aligned}
25(\mathrm{OH}) \mathrm{D} \text { level }= & \beta_{0}+\beta_{1} \sin (2 \pi \mathrm{m} / 12) \\
& +\beta_{2} \cos (2 \pi \mathrm{m} / 12) .
\end{aligned}
$$

Deseasonalized values [27] were calculated by taking each subject's measured value, subtracting the predicted value and adding back the overall mean. Deseasonalized values were used for analysis.

Table 1 Number of mother-child pairs by vitamin $D$ and fecal data time points (data as $N[\%]$ )

\begin{tabular}{llll}
\hline \multirow{2}{*}{ Vitamin D sample } & \multicolumn{3}{l}{ Fecal collection time points } \\
\cline { 2 - 4 } 1 month & 6 months & Both \\
\hline Prenatal & $53(31.2 \%)$ & $44(34.4 \%)$ & $61(30.4 \%)$ \\
Cord & $31(18.2 \%)$ & $29(22.6 \%)$ & $36(17.9 \%)$ \\
Both & $86(50.6 \%)$ & $55(43.0 \%)$ & $104(51.7 \%)$ \\
\hline
\end{tabular}

\section{Statistical analysis}

Significance for main effects was pre-specified at $p<0.05$ and for interaction effects at $p<0.1$. Compositional differences in the gut microbiota by maternal and cord blood 25(OH)D measures were assessed by permutational multivariate analysis of variance as implemented in the R package "vegan" [28], using both weighted and unweighted UniFrac [29]. Alpha diversity indices (richness, Pielou's evenness, and Faith's phylogenetic diversity) were calculated using QIIME [18] and the R vegan package [28], and tested for associations with maternal and cord blood 25(OH)D using linear regression. Individual taxa tests were conducted on all OTUs found in $10 \%$ or more of samples using zero-inflated negative binomial regression (or the standard negative binomial if convergence failed). $P$-values were corrected using the Benjamini and Hochberg [30] false discovery rate; false discovery rate adjusted $p<0.05$ was considered significant. We a priori hypothesized that race may confound and/or modify associations between maternal and cord blood $25(\mathrm{OH}) \mathrm{D}$ and infant gut microbiota, thus all analyses were adjusted for maternal race (Black versus White, excluding others) and we also tested for racespecific effects with stratified models and interaction terms.

Finally, as breastfeeding is associated with early-life gut microbiota [15] and with lower levels of vitamin D in infancy [31], we hypothesized that breastfeeding could modify associations of maternal and cord blood $25(\mathrm{OH}) \mathrm{D}$ with gut microbiota. For each microbiota time-point ( 1 or 6 months), current breastfeeding was defined as any current breastfeeding at that timepoint. Interaction terms were fit between maternal or cord $25(\mathrm{OH}) \mathrm{D}$ and current breastfeeding to examine potential effect modification.

\section{Results}

\section{Basic descriptives}

Table 2 presents demographic information comparing characteristics of those included in the analytic sample to those not included. Compared to those not included in the sample, those included were slightly older, and were more often White, married, non-urban dwelling, had higher incomes and were less likely to be exposed to environmental tobacco smoke prenatally (all $p<0.05$ ). Mean birth weight Z-score of children in the analytic sample was also higher.

Mean prenatal 25(OH)D was $25.04 \pm 11.62 \mathrm{ng} / \mathrm{mL}$, while mean cord blood $25(\mathrm{OH}) \mathrm{D}$ was $10.88 \pm 6.77 \mathrm{ng} / \mathrm{mL}$. Among the 403 mothers with prenatal 25(OH)D measurements, 141 (35\%) had insufficient prenatal vitamin D $(25[\mathrm{OH}] \mathrm{D}<20 \mathrm{ng} / \mathrm{mL})$. Prenatal and cord $25(\mathrm{OH}) \mathrm{D}$ were highly correlated (Pearson $\rho=0.81, p<0.001$ ). 
Table 2 Characteristics of participants included and excluded from analysis (data as mean \pm SD or $\mathrm{N}(\%)$ )

\begin{tabular}{|c|c|c|c|}
\hline \multirow[b]{2}{*}{ Covariate } & \multicolumn{2}{|c|}{ Included in analysis subset } & \multirow[b]{2}{*}{$p$-value } \\
\hline & No $(N=759)$ & Yes $(N=499)$ & \\
\hline Maternal age (years) & $29.2 \pm 5.2$ & $30.1 \pm 5.2$ & 0.002 \\
\hline \multicolumn{4}{|l|}{ Maternal race } \\
\hline White & $150(19.8 \%)$ & $140(28.1 \%)$ & 0.001 \\
\hline Black & $497(65.5 \%)$ & $281(56.3 \%)$ & \\
\hline Other & $112(14.8 \%)$ & $78(15.6 \%)$ & \\
\hline \multicolumn{4}{|l|}{ Mother married } \\
\hline No & $318(41.9 \%)$ & $167(33.5 \%)$ & 0.003 \\
\hline Yes & $441(58.1 \%)$ & $332(66.5 \%)$ & \\
\hline \multicolumn{4}{|l|}{ Urban residence } \\
\hline No & 299 (39.4\%) & $256(51.3 \%)$ & $<.001$ \\
\hline Yes & $460(60.6 \%)$ & $243(48.7 \%)$ & \\
\hline \multicolumn{4}{|l|}{ Household income } \\
\hline$<\$ 40,000$ & $328(43.2 \%)$ & 149 (29.9\%) & $<.001$ \\
\hline$\$ 40,000-\$ 80,000$ & $210(27.7 \%)$ & $137(27.5 \%)$ & \\
\hline$\$ 80,000+$ & $139(18.3 \%)$ & $144(28.9 \%)$ & \\
\hline Refused/did not answer & $82(10.8 \%)$ & $69(13.8 \%)$ & \\
\hline$G$ estational age $\mathrm{e}^{\mathrm{a}}$ & $38.7 \pm 1.8$ & $38.8 \pm 1.6$ & 0.27 \\
\hline Birthweight z-score ${ }^{b}$ & $-0.196 \pm 0.972$ & $-0.005 \pm 1.004$ & 0.001 \\
\hline \multicolumn{4}{|l|}{ First born child } \\
\hline No & $492(64.8 \%)$ & $306(61.3 \%)$ & 0.21 \\
\hline Yes & $267(35.2 \%)$ & $193(38.7 \%)$ & \\
\hline \multicolumn{4}{|l|}{ Mode of delivery } \\
\hline Vaginal & $456(60.6 \%)$ & $328(65.9 \%)$ & 0.061 \\
\hline C-Section & $296(39.4 \%)$ & $170(34.1 \%)$ & \\
\hline \multicolumn{4}{|l|}{ Season of birth } \\
\hline Winter & $156(20.6 \%)$ & $101(20.2 \%)$ & 0.53 \\
\hline Spring & $182(23.9 \%)$ & $103(20.6 \%)$ & \\
\hline Summer & $202(26.6 \%)$ & $143(28.7 \%)$ & \\
\hline Fall & 219 (28.9\%) & $152(30.5 \%)$ & \\
\hline \multicolumn{4}{|c|}{ Environmental tobacco smoke at pre-delivery } \\
\hline No & $517(68.1 \%)$ & $394(79 \%)$ & $<.001$ \\
\hline Yes & $242(31.9 \%)$ & $105(21 \%)$ & \\
\hline
\end{tabular}

${ }^{*}$ Calculated by analysis of variance for numerical covariates and chi-square test for categorical covariates

${ }^{\mathrm{a}} \mathrm{N}=737$ for $\mathrm{No}$ and $N=495$ for Yes

${ }^{\mathrm{b}} \mathrm{N}=700$ for $\mathrm{No}$ and $N=472$ for Yes

\section{Association of prenatal and cord blood 25(OH)D with gut} microbiota alpha diversity

After adjusting for race, higher prenatal 25(OH)D level was significantly associated with decreased richness $(p=$ $0.028)$ and diversity $(p=0.012)$ of the gut microbiota at 1 month of age. There were no other main effects of prenatal or cord $25(\mathrm{OH}) \mathrm{D}$ levels on the infant gut microbiota at 1 or 6 months of age after adjusting for race (Table 3).
There was evidence that race modified associations between cord blood 25(OH)D and alpha diversity metrics of the infant gut microbiota at 1 and 6 months (Table 3 ). There was evidence for a race-specific effect between cord 25(OH)D level and microbial evenness at 1-month (interaction $p=0.016$ ), where higher cord 25(OH)D level was associated with higher infant gut evenness, but only among White women $(p=0.044)$. Although there was evidence of a race-specific effect of cord 25(OH)D on richness at 1 month (interaction $p=0.079$ ) with higher cord $25(\mathrm{OH}) \mathrm{D}$ inversely associated with richness only in Blacks; in models stratified by race this effect was not statistically significant. Race also modified the association of cord $25(\mathrm{OH}) \mathrm{D}$ with infant gut evenness at the 6 month visit (interaction $p=0.053$ ); in Black women, higher cord $25(\mathrm{OH}) \mathrm{D}$ was associated with decreased infant gut evenness $(p=0.025)$ but there was no association in White children $(p=0.475)$.

There was no evidence current breastfeeding modified associations of maternal or cord $25(\mathrm{OH}) \mathrm{D}$ and 1- or 6month infant gut microbiota alpha diversity metrics (all interaction $p>0.42$ ).

\section{Association of prenatal and cord blood vitamin D with gut microbiota composition}

After adjusting for race, both prenatal ( $p=0.029$ for unweighted UniFrac, $p=0.030$ for weighted UniFrac) and cord $25(\mathrm{OH}) \mathrm{D}(p=0.028$ for unweighted UniFrac, $p=$ 0.044 for weighted UniFrac) levels were significantly associated with 1-month microbiota composition, though only a small proportion of variability in microbiota composition was explained by maternal or cord vitamin $\mathrm{D}$ (Table 4). No significant associations were found between prenatal and cord 25(OH)D levels and microbiota composition at 6 months of age, after adjusting for race (Table 4). There was evidence of a race-specific effect of prenatal $25(\mathrm{OH}) \mathrm{D}$ on 1-month infant gut microbiota composition (interaction $p=0.089$ ), with associations in Black ( $p=0.006$ for weighted UniFrac) but not White women ( $p=0.375$ for weighted UniFrac). There was no evidence that current breastfeeding modified associations of maternal or cord 25(OH)D and 1- or 6-month infant gut microbiota composition (all interaction $p>$ 0.40).

Based on compositional difference testing, individual OTU tests were conducted to associate deseasonalized prenatal and cord $25(\mathrm{OH}) \mathrm{D}$ level with 1-month infant gut OTUs only, after adjusting for maternal race (Fig. 1). In the 1-month samples, a total of 6 OTUs were significantly associated with prenatal $25(\mathrm{OH}) \mathrm{D}$ levels while 11 OTUs were significantly associated with cord 25(OH)D. The majority of significant OTUs were positively associated with prenatal and cord $25(\mathrm{OH}) \mathrm{D}$ levels (4/6 for prenatal vitamin $\mathrm{D} ; 10 / 11$ for cord vitamin $\mathrm{D})$. Three OTUs 
Table 3 Alpha diversity metrics by deseasonalized maternal Vitamin D, overall and by race

\begin{tabular}{|c|c|c|c|c|}
\hline Outcome & Model & $\beta^{a}$ & SE & $p$-value \\
\hline \multicolumn{5}{|l|}{ 1-Month } \\
\hline \multicolumn{5}{|c|}{ Prenatal Vitamin D } \\
\hline \multirow[t]{5}{*}{ Richness } & Overall (unadjusted) & -4.872 & 1.201 & $<.001$ \\
\hline & Overall (adjusted for race) ${ }^{b}$ & -3.293 & 1.488 & 0.028 \\
\hline & Black & -4.409 & 1.912 & 0.022 \\
\hline & White & -1.548 & 2.371 & 0.515 \\
\hline & Interaction $p$-value & & & 0.35 \\
\hline \multirow[t]{5}{*}{ Evenness } & Overall (unadjusted) & -0.004 & 0.002 & 0.046 \\
\hline & Overall (adjusted for race) ${ }^{b}$ & -0.002 & 0.003 & 0.498 \\
\hline & Black & -0.004 & 0.003 & 0.26 \\
\hline & White & 0.001 & 0.004 & 0.76 \\
\hline & Interaction $p$-value & & & 0.347 \\
\hline \multirow[t]{5}{*}{ Diversity } & Overall (unadjusted) & -0.293 & 0.063 & $<.001$ \\
\hline & Overall (adjusted for race) & -0.199 & 0.079 & 0.012 \\
\hline & Black & -0.281 & 0.101 & 0.006 \\
\hline & White & -0.071 & 0.125 & 0.567 \\
\hline & Interaction $p$-value & & & 0.195 \\
\hline \multicolumn{5}{|c|}{ Cord Vitamin D } \\
\hline \multirow[t]{5}{*}{ Richness } & Overall (unadjusted) & -6.363 & 2.306 & 0.006 \\
\hline & Overall (adjusted for race) ${ }^{b}$ & -2.001 & 2.660 & 0.453 \\
\hline & Black & -5.955 & 3.455 & 0.087 \\
\hline & White & 3.516 & 4.126 & 0.397 \\
\hline & Interaction $p$-value & & & 0.079 \\
\hline \multirow[t]{5}{*}{ Evenness } & Overall (unadjusted) & -0.005 & 0.004 & 0.219 \\
\hline & Overall (adjusted for race) ${ }^{b}$ & 0.002 & 0.005 & 0.712 \\
\hline & Black & -0.009 & 0.007 & 0.194 \\
\hline & White & 0.017 & 0.008 & 0.044 \\
\hline & Interaction $p$-value & & & 0.016 \\
\hline \multirow[t]{5}{*}{ Diversity } & Overall (unadjusted) & -0.385 & 0.122 & 0.002 \\
\hline & Overall (adjusted for race) ${ }^{b}$ & -0.174 & 0.142 & 0.223 \\
\hline & Black & -0.370 & 0.191 & 0.055 \\
\hline & White & 0.100 & 0.206 & 0.629 \\
\hline & Interaction $p$-value & & & 0.103 \\
\hline \multicolumn{5}{|l|}{ 6-Months } \\
\hline \multicolumn{5}{|c|}{ Prenatal Vitamin D } \\
\hline \multirow[t]{5}{*}{ Richness } & Overall (unadjusted) & -4.447 & 1.513 & 0.004 \\
\hline & Overall (adjusted for race) & -2.324 & 1.852 & 0.211 \\
\hline & Black & -2.364 & 2.590 & 0.363 \\
\hline & White & -2.276 & 2.626 & 0.388 \\
\hline & Interaction $p$-value & & & 0.981 \\
\hline \multirow[t]{4}{*}{ Evenness } & Overall (unadjusted) & -0.004 & 0.002 & 0.097 \\
\hline & Overall (adjusted for race) ${ }^{b}$ & -0.001 & 0.003 & 0.643 \\
\hline & Black & 0.000 & 0.004 & 0.973 \\
\hline & White & -0.003 & 0.005 & 0.553 \\
\hline
\end{tabular}


Table 3 Alpha diversity metrics by deseasonalized maternal Vitamin D, overall and by race (Continued)

\begin{tabular}{|c|c|c|c|c|}
\hline Outcome & Model & $\beta^{a}$ & SE & $p$-value \\
\hline & Interaction $p$-value & & & 0.648 \\
\hline \multirow[t]{5}{*}{ Diversity } & Overall (unadjusted) & -0.229 & 0.075 & 0.003 \\
\hline & Overall (adjusted for race) ${ }^{b}$ & -0.116 & 0.091 & 0.206 \\
\hline & Black & -0.167 & 0.128 & 0.195 \\
\hline & White & -0.055 & 0.128 & 0.667 \\
\hline & Interaction $p$-value & & & 0.544 \\
\hline \multicolumn{5}{|c|}{ Cord Vitamin D } \\
\hline \multirow[t]{5}{*}{ Richness } & Overall (unadjusted) & -8.437 & 2.860 & 0.004 \\
\hline & Overall (adjusted for race) ${ }^{b}$ & -6.181 & 3.300 & 0.063 \\
\hline & Black & -10.201 & 4.241 & 0.018 \\
\hline & White & 0.673 & 5.153 & 0.897 \\
\hline & Interaction p-value & & & 0.112 \\
\hline \multirow[t]{5}{*}{ Evenness } & Overall (unadjusted) & -0.007 & 0.005 & 0.166 \\
\hline & Overall (adjusted for race) ${ }^{b}$ & -0.008 & 0.006 & 0.177 \\
\hline & Black & -0.017 & 0.007 & 0.025 \\
\hline & White & 0.007 & 0.010 & 0.475 \\
\hline & Interaction $p$-value & & & 0.053 \\
\hline \multirow[t]{5}{*}{ Diversity } & Overall (unadjusted) & -0.409 & 0.140 & 0.004 \\
\hline & Overall (adjusted for race) ${ }^{b}$ & -0.300 & 0.159 & 0.061 \\
\hline & Black & -0.479 & 0.205 & 0.021 \\
\hline & White & 0.006 & 0.248 & 0.979 \\
\hline & Interaction p-value & & & 0.141 \\
\hline
\end{tabular}

SE standard error

${ }^{\text {a } E s t i m a t e d ~ c h a n g e ~ i n ~ a l p h a ~ d i v e r s i t y ~ m e a s u r e ~ f o r ~ a ~} 5 \mathrm{ng} / \mathrm{mL}$ increase in vitamin $D$

${ }^{b}$ Restricted to Black or White only, so reduced sample size compared to unadjusted

Table 4 Compositional differences by deseasonalized maternal vitamin D, overall and by race

\begin{tabular}{|c|c|c|c|c|c|c|c|c|}
\hline & \multicolumn{4}{|l|}{ 1-Month } & \multicolumn{4}{|c|}{ 6-Month } \\
\hline & \multicolumn{2}{|c|}{ Unweighted UniFrac } & \multicolumn{2}{|c|}{ Weighted UniFrac } & \multicolumn{2}{|c|}{ Unweighted UniFrac } & \multicolumn{2}{|c|}{ Weighted UniFrac } \\
\hline & $p$-value & $R^{2}$ & $p$-value & $R^{2}$ & $p$-value & $R^{2}$ & $p$-value & $R^{2}$ \\
\hline \multicolumn{9}{|l|}{ Prenatal Vitamin D } \\
\hline Overall (unadjusted) & $<0.001$ & 0.013 & 0.042 & 0.008 & 0.001 & 0.009 & 0.490 & 0.003 \\
\hline Overall (adjusted for race) ${ }^{a}$ & 0.029 & 0.006 & 0.030 & 0.011 & 0.212 & 0.005 & 0.719 & 0.002 \\
\hline Black & 0.001 & 0.014 & 0.006 & 0.023 & 0.037 & 0.011 & 0.973 & 0.001 \\
\hline White & 0.903 & 0.008 & 0.375 & 0.012 & 0.609 & 0.01 & 0.614 & 0.008 \\
\hline Interaction $p$-value & 0.157 & & 0.089 & & 0.144 & & 0.871 & \\
\hline \multicolumn{9}{|l|}{ Cord Vitamin D } \\
\hline Overall (unadjusted) & 0.001 & 0.009 & 0.097 & 0.007 & 0.001 & 0.01 & 0.690 & 0.003 \\
\hline Overall (adjusted for race) ${ }^{a}$ & 0.028 & 0.007 & 0.044 & 0.011 & 0.234 & 0.006 & 0.938 & 0.001 \\
\hline Black & 0.006 & 0.014 & 0.053 & 0.016 & 0.032 & 0.013 & 0.697 & 0.005 \\
\hline White & 0.782 & 0.011 & 0.442 & 0.013 & 0.956 & 0.010 & 0.805 & 0.007 \\
\hline Interaction $p$-value & 0.292 & & 0.516 & & 0.350 & & 0.527 & \\
\hline
\end{tabular}

${ }^{a}$ Restricted to Black or White only, so reduced sample size compared to unadjusted 


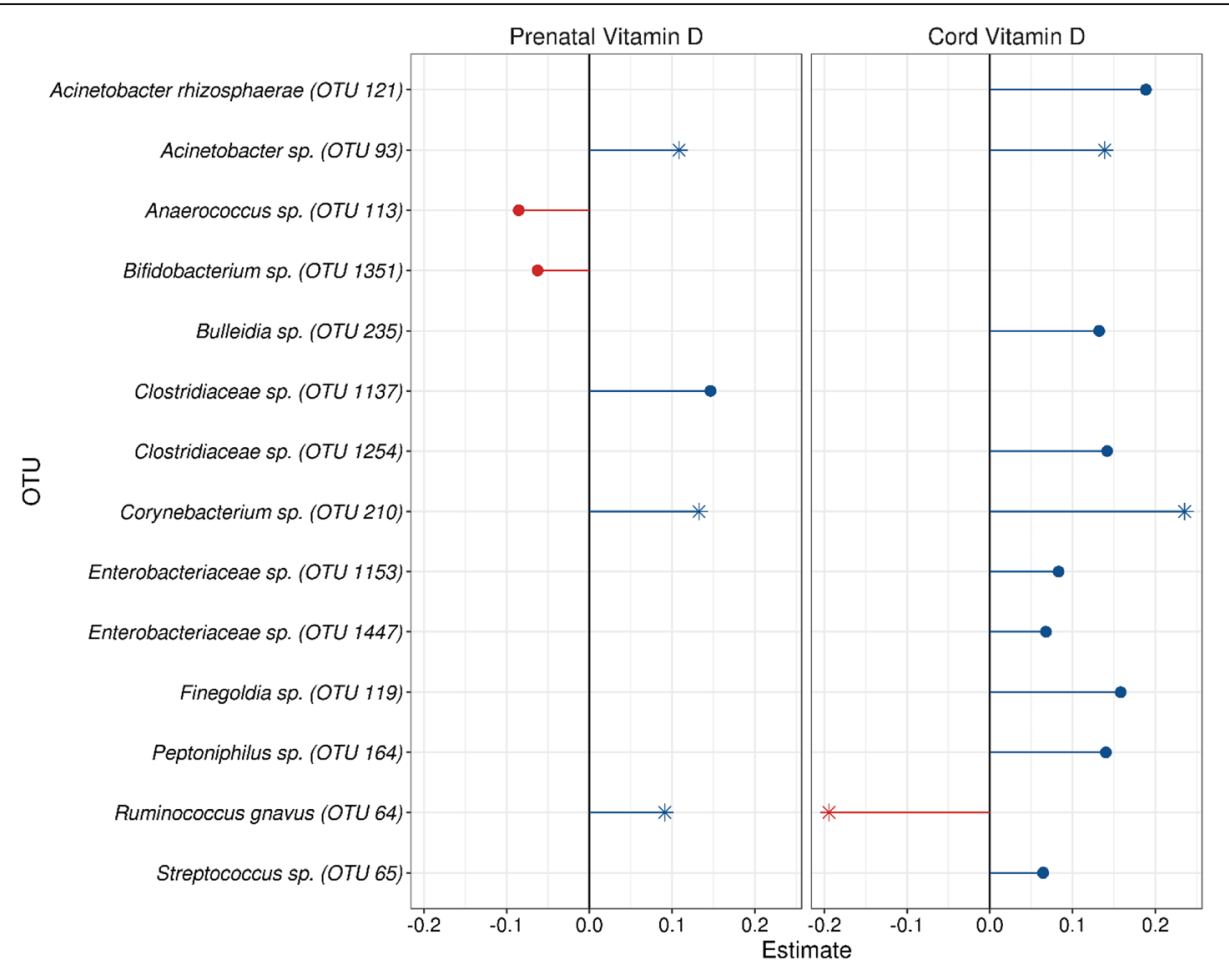

Fig. 1 Association between deseasonalized vitamin D (prenatal and cord) and 1-month specific OTUs, after adjusting for maternal race. Plot displays all significant taxa (false discovery rate adjusted $p<0.05$ ). OTUs significantly associated with both prenatal and cord vitamin $\mathrm{D}$ are indicated by an asterisk (*). The $y$-axis displays the specific OTU and the $x$-axis is the negative binomial regression coefficient. OTUs are colored by direction of association (blue (right side) = positive association, red (left side) = negative association). Abbreviations: OTU, operational taxonomic units

were significantly associated with both prenatal and cord 25(OH)D: OTU 93 (Acinetobacter) and OTU 210 (Corynebacterium), which were consistently positively associated with both prenatal and cord $25(\mathrm{OH}) \mathrm{D}$, as well as OTU 64 (Ruminococcus gnavus), which was positively associated with prenatal $25(\mathrm{OH}) \mathrm{D}$, but negatively associated with cord $25(\mathrm{OH}) \mathrm{D}$.

\section{Discussion}

In this racially diverse unselected birth cohort, we found evidence that prenatal and cord blood vitamin D levels were associated with early life ( 1 month) gut microbiota. Conversely, there was no association of prenatal or cord blood vitamin D and gut microbiota measured at 6 months of age. This work extends that of previous studies of maternal vitamin D and the infant gut microbiome $[11,12]$ and provides new data on the associations of cord blood vitamin $\mathrm{D}$ level and the infant gut microbiome.

While some associations were unique, there were 3 OTUs in the 1 month gut microbiota significantly associated with both prenatal and cord blood 25(OH)D. Prenatal and cord blood 25(OH)D were both positively associated with Acinetobacter and Corynebacterium OTUs; in contrast, a Ruminococcus gnavus OTU was positively associated with prenatal $25(\mathrm{OH}) \mathrm{D}$ but negatively associated with cord blood 25(OH)D. Similar to our findings, Lundgren, Madan [32] found that Acinetobacter in stool samples (collected at 6 weeks) of newborns delivered via $\mathrm{C}$-section was positively associated with maternal dairy intake, presuming increased maternal dairy intake is associated with higher vitamin D. Ooi, Li [8] found that defective vitamin D receptors in mice were associated with lower Ruminococcaceae, which is consistent with our findings with prenatal but not cord blood 25(OH)D.

Only 2 other studies have compared prenatal vitamin D level with infant gut microbiome. The KOALA Dutch cohort study composed of 913 mother-infant pairs assessed the association between prenatal 25(OH)D levels with the abundance of predefined bacterial taxa (Bifidobacteria, Escherichia coli, Bacteroides fragilis, Clostridium difficile, and Lactobacilli) in stool samples of children at 1 month of age [11]. Maternal 25(OH)D quintiles were negatively associated with counts of Bifidobacterium species but positively associated with counts of B. fragilis [11]. Similarly, prenatal 25(OH)D levels in WHEALS were inversely associated with Bifidobacterium species at 1 month. In contrast to our study, which utilized 16S rRNA V4 sequencing and did not a 
priori target specific bacterial taxa, in the KOALA cohort only specific bacterial groups were measured, thus relationships between $25(\mathrm{OH}) \mathrm{D}$ and other gut bacteria not measured in that study may have been missed. In a study population of 333 ethnically diverse mother-infant pairs that were part of a larger clinical trial, cord $25(\mathrm{OH}) \mathrm{D}$ levels were associated with increased levels of Lachnospiraceae and unclassified Clostridiales but decreased levels of Lactococcus [12]. In contrast to the unselected WHEALS cohort, this population was composed of children at higher risk for asthma.

Mechanistically, vitamin D could potentially impact gut microbiome structure and function via several mechanisms. Vitamin D receptor knockout status influences homeostasis in the intestines and gut microbiome of mice [7]. The active form of vitamin D (1,25-dihydroxycholecalciferol) and vitamin D receptor knockouts can affect the gut microbiome indirectly by reducing inflammation; gut inflammation provides pathogens with substrates that allow them to proliferate at the expense of more beneficial bacterial species [8]. Vitamin D may also impact the gut microbiome by upregulating innate immunity, producing antimicrobial peptides by macrophages, maintaining the function of the intestinal barrier and by altering calcium and phosphate absorption [33]. Additional research on potential mechanisms by which vitamin $\mathrm{D}$ influences the gut microbiome are needed.

In the current study, there were some inconsistent findings across the different time points of measurement. During pregnancy, the fetus's only source of vitamin $\mathrm{D}$ is via the mother. However, after birth, the child transitions to obtaining vitamin $\mathrm{D}$ from direct sun exposure, dietary supplements and food (breastfeeding or formula feeding). Around the time of WHEALS births, in 2003, the American Academy of Pediatrics recommendations were that all breastfed infants, or non-breastfed infants who received less than $500 \mathrm{~mL}$ of vitamin D-fortified formula or milk, be given $400 \mathrm{IU}$ of vitamin D per day [34]. We do not have information on whether or not the WHEALS children were supplemented with vitamin D in early life, thus we are unable to account for this potential postnatal factor. In WHEALS, although the association between prenatal and cord blood $25(\mathrm{OH}) \mathrm{D}$ is strong $(r=0.75)$, when maternal $25(\mathrm{OH}) \mathrm{D}$ is below a certain threshold $(<15 \mathrm{ng} / \mathrm{mL})$, the correlation is weaker $(r=0.16)$ [14]. These findings suggest there exists a maternal vitamin $\mathrm{D}$ threshold below which mothers may insufficiently contribute to cord blood $25(\mathrm{OH}) \mathrm{D}$ and could partially explain why prenatal and cord 25(OH)D did not identically impact the infant gut microbiota.

We found evidence for race-specific effects of $25(\mathrm{OH}) \mathrm{D}$ on the infant microbiota. Studies have shown vitamin $\mathrm{D}$ levels vary among race groups, and this extends to the neonate [35]. Further, the correlation of prenatal and cord blood 25(OH)D is weaker among Black than White children $(r=0.65$ and $r=0.87$ respectively) [36]. Lower 25(OH)D levels among Blacks as compared to Whites can be explained by several factors. Darker skin pigmentation and thickness reduces levels of vitamin D production in the skin, a major source of vitamin D in the body [37, 38]. In general, Blacks consume less dietary vitamin D and milk products compared to Whites [37]. These racial differences can also be explained by genetic factors. Blacks have lower levels of vitamin D-binding protein, a serum transport protein, which contributes to lower levels of vitamin D [38]. Future studies are needed to better understand mechanisms, including genetic, dietary and/or cultural factors, that may explain why race modifies the association of $25(\mathrm{OH}) \mathrm{D}$ and the infant gut microbiota.

Given that we found associations between maternal and cord blood vitamin D and the infant gut microbiota at 1 , but not 6 , months of age, it is possible that maternal vitamin $\mathrm{D}$ level influences long-term offspring health through mechanisms other than the gut microbiome. Besides the microbiome, alternative mechanisms through which maternal vitamin $\mathrm{D}$ may influence child health includes suppression of inflammation [39] or epigenetic alternation [40].

In addition to future studies of these mechanisms, future studies should also consider obtaining meconium as a biospecimen for measuring the gut microbiome for additional studies on the impact of maternal vitamin D level and infant gut microbiome more proximal to the time of seeding.

Our study has a number of strengths and limitations. Our sample has considerable racial, educational and socioeconomic diversity and the early timeframe at which stool samples were collected $(1$ and 6 months), which allows for examination of the infant gut microbiome early on, presumably before external environmental exposure (i.e., diet diversity) has major impacts on composition. However, stool samples were only collected at 2 time points; given the rapidity of the development of the gut microbiome after birth, future studies should collect more samples over the first year of life. We do not have data on the infants' vitamin $\mathrm{D}$ levels after birth nor do we have data on infants' use of supplements after birth. However, because the vitamin D levels were measured prenatally and in cord blood, before the time of stool sample collection for gut microbiota measurement, it is unlikely that our results are due to reverse causality. There were significant differences between the participants that were included and excluded from the analytical sample, thus our results may be subject to selection bias. 


\section{Conclusion}

Prenatal maternal blood and cord blood 25(OH)D levels are associated with the very early life gut microbiota. Maternal vitamin D levels during pregnancy are associated with health in childhood, including obesity [4], allergy, and asthma [3]. Similar to vitamin D, the gut microbiome influences human health and disease and has also been shown to be associated with obesity [41], allergy, and asthma [25]. Future studies should examine if the gut microbiome mediates associations between vitamin $\mathrm{D}$ and disease or if the gut microbiome and vitamin D may interact to influence health and disease.

\section{Abbreviations}

25[OH]D: 25-hydroxyvitamin D; OTU: Operational taxonomic unit; SD: Standard deviation; WHEALS: Wayne County Health, Environment, Allergy and Asthma Longitudinal Study

\section{Acknowledgements}

Not Applicable.

\section{Authors' contributions}

ZK and ACB drafted the manuscript. AS performed all analyses. CCJ designed the original study. All authors read, revised and approved the final manuscript.

\section{Funding}

This study was supported by the National Institutes of Health (R01 Al050681, R01 HL113010, R01 HD082147, and P01 Al089473) and the Fund for Henry Ford Hospital. The funders played no role in the design of the study, the collection, analysis, or interpretation of the data or in writing the manuscript.

\section{Availability of data and materials}

The datasets used and/or analyzed during the current study are available from the corresponding author on reasonable request and with appropriate approvals.

\section{Ethics approval and consent to participate}

All participants provided written, informed consent and study protocols were approved by the Institutional Review Board at Henry Ford Health System.

\section{Consent for publication}

Not applicable.

\section{Competing interests}

The authors declare that they have no competing interests.

\section{Author details}

${ }^{1}$ Department of Public Health Sciences, Henry Ford Hospital, 1 Ford Place, 5C, Detroit, MI 48202, USA. ²Department of Medicine, University of California, San Francisco, CA, USA. ${ }^{3}$ Department of Pediatrics, University of Alberta, Alberta, Canada. ${ }^{4}$ Division of Allergy and Clinical Immunology, Department of Pediatrics, Georgia Regents University, Augusta, GA, USA. ${ }^{5}$ Center for Urban Responses to Environmental Stressors, Wayne State University, Detroit, MI, USA.

Received: 13 February 2020 Accepted: 8 October 2020 Published online: 20 October 2020

\section{References}

1. Wagner $\mathrm{CL}$, Hollis BW, Kotsa K, Fakhoury H, Karras SN. Vitamin D administration during pregnancy as prevention for pregnancy, neonatal and postnatal complications. Rev Endocr Metab Disord. 2017;18(3):307-22.

2. ACOG Committee on Obstetric Practice. ACOG committee opinion No. 495: vitamin D: screening and supplementation during pregnancy. Obstet Gynecol. 2011;118(1):197-8.
3. Wegienka G, Havstad S, Zoratti EM, Kim H, Ownby DR, Johnson CC. Association between vitamin $\mathrm{D}$ levels and allergy-related outcomes vary by race and other factors. J Allergy Clin Immunol. 2015;136(5):1309-14 e1-4.

4. Daraki V, Roumeliotaki T, Chalkiadaki G, Katrinaki M, Karachaliou M, Leventakou $\mathrm{V}$, et al. Low maternal vitamin $\mathrm{D}$ status in pregnancy increases the risk of childhood obesity. Pediatr Obes. 2018;13(8):467-75.

5. Antonucci R, Locci C, Clemente MG, Chicconi E, Antonucci L. Vitamin D deficiency in childhood: old lessons and current challenges. J Pediatr Endocrinol Metab. 2018;31(3):247-60.

6. Ly NP, Litonjua A, Gold DR, Celedon JC. Gut microbiota, probiotics, and vitamin D: interrelated exposures influencing allergy, asthma, and obesity? J Allergy Clin Immunol. 2011;127(5):1087-94 quiz 95-6.

7. Jin D, Wu S, Zhang YG, Lu R, Xia Y, Dong H, et al. Lack of vitamin D receptor causes dysbiosis and changes the functions of the murine intestinal microbiome. Clin Ther. 2015;37(5):996-1009.e7.

8. Ooi JH, Li Y, Rogers CJ, Cantorna MT. Vitamin D regulates the gut microbiome and protects mice from dextran sodium sulfate-induced colitis. J Nutr. 2013;143(10):1679-86.

9. Waterhouse M, Hope B, Krause L, Morrison M, Protani MM, Zakrzewski M, et al. Vitamin $D$ and the gut microbiome: a systematic review of in vivo studies. Eur J Nutr. 2019;58(7):2895-910.

10. Mandal S, Godfrey KM, McDonald D, Treuren WV, Bjørnholt JV, Midtvedt T, et al. Fat and vitamin intakes during pregnancy have stronger relations with a pro-inflammatory maternal microbiota than does carbohydrate intake. Microbiome. 2016;4(1):55.

11. Talsness CE, Penders J, Jansen E, Damoiseaux J, Thijs C, Mommers M. Influence of vitamin D on key bacterial taxa in infant microbiota in the KOALA birth cohort study. PLoS One. 2017;12(11):e0188011.

12. Sordillo JE, Zhou Y, McGeachie MJ, Ziniti J, Lange N, Laranjo N, et al. Factors influencing the infant gut microbiome at age 3-6 months: findings from the ethnically diverse Vitamin D Antenatal Asthma Reduction Trial (VDAA RT). J Allergy Clin Immunol. 2017;139(2):482-91.e14.

13. Ferretti P, Pasolli E, Tett A, Asnicar F, Gorfer V, Fedi S, et al. Mother-to-infant microbial transmission from different body sites shapes the developing infant gut microbiome. Cell Host Microbe. 2018;24(1):133-45.e5.

14. Wegienka G, Kaur H, Sangha R, Cassidy-Bushrow AE. Maternal-cord blood vitamin D correlations vary by maternal levels. J Pregnancy. 2016;2016:6.

15. Levin AM, Sitarik AR, Havstad SL, Fujimura KE, Wegienka G, Cassidy-Bushrow $A E$, et al. Joint effects of pregnancy, sociocultural, and environmental factors on early life gut microbiome structure and diversity. Sci Rep. 2016;6:31775.

16. Caporaso JG, Lauber CL, Walters WA, Berg-Lyons D, Huntley J, Fierer N, et al. Ultra-high-throughput microbial community analysis on the Illumina HiSeq and MiSeq platforms. ISME J. 2012;6(8):1621-4.

17. Magoc T, Salzberg SL. FLASH: fast length adjustment of short reads to improve genome assemblies. Bioinformatics. 2011;27(21):2957-63.

18. Caporaso JG, Kuczynski J, Stombaugh J, Bittinger K, Bushman FD, Costello EK, et al. QIIME allows analysis of high-throughput community sequencing data. Nat Methods. 2010;7(5):335-6.

19. Edgar RC, Haas BJ, Clemente JC, Quince C, Knight R. UCHIME improves sensitivity and speed of chimera detection. Bioinformatics. 2011;27(16): 2194-200.

20. Edgar RC. Search and clustering orders of magnitude faster than BLAST. Bioinformatics. 2010;26(19):2460-1.

21. McDonald D, Price MN, Goodrich J, Nawrocki EP, DeSantis TZ, Probst A, et al. An improved Greengenes taxonomy with explicit ranks for ecological and evolutionary analyses of bacteria and archaea. ISME J. 2012;6(3):610-8.

22. Caporaso JG, Bittinger K, Bushman FD, DeSantis TZ, Andersen GL, Knight R. PyNAST: a flexible tool for aligning sequences to a template alignment. Bioinformatics. 2010;26(2):266-7.

23. Wang Q, Garrity GM, Tiedje JM, Cole JR. Naive Bayesian classifier for rapid assignment of rRNA sequences into the new bacterial taxonomy. Appl Environ Microbiol. 2007;73(16):5261-7.

24. Price MN, Dehal PS, Arkin AP. FastTree: computing large minimum evolution trees with profiles instead of a distance matrix. Mol Biol Evol. 2009;26(7): $1641-50$.

25. Fujimura KE, Sitarik AR, Havstad S, Lin DL, Levan S, Fadrosh D, et al. Neonatal gut microbiota associates with childhood multisensitized atopy and T cell differentiation. Nat Med. 2016;22(10):1187-91.

26. Binkley N, Krueger DC, Morgan S, Wiebe D. Current status of clinical 25hydroxyvitamin D measurement: an assessment of between-laboratory agreement. Clin Chim Acta. 2010;411(23-24):1976-82. 
27. van der Mei IA, Ponsonby AL, Dwyer T, Blizzard L, Taylor BV, Kilpatrick T, et al. Vitamin D levels in people with multiple sclerosis and community controls in Tasmania, Australia. J Neurol. 2007;254(5):581-90.

28. Oksanen J, Blanchet FG, Kindt R, Legendre P, Minchin P, O'Hara RB, et al. Vegan: Community ecology package. R package version 2.0-2. 2012. Available from: https://cran.r-project.org/package=vegan

29. Lozupone C, Lladser ME, Knights D, Stombaugh J, Knight R. UniFrac: an effective distance metric for microbial community comparison. ISME J. 2011; 5(2):169-72.

30. Benjamini $Y$, Hochberg $Y$. Controlling the false discovery rate: a practical and powerful approach to multiple testing. J R Stat Soc Ser B Methodol. 1995;57(1):289-300.

31. Ostergard M, Arnberg K, Michaelsen KF, Madsen AL, Krarup H, Trolle E, et al. Vitamin D status in infants: relation to nutrition and season. Eur J Clin Nutr. 2011:65(5):657-60.

32. Lundgren SN, Madan JC, Emond JA, Morrison HG, Christensen BC, Karagas $M R$, et al. Maternal diet during pregnancy is related with the infant stool microbiome in a delivery mode-dependent manner. Microbiome. 2018;6(1): 109.

33. Waterhouse M, Hope B, Krause L, Morrison M, Protani MM, Zakrzewski M et al. Vitamin $D$ and the gut microbiome: a systematic review of in vivo studies. Eur J Nutr. 2018.

34. Gartner LM, Greer FR, Section on Breastfeeding and Committee on Nutrition, American Academy of Pediatrics. Prevention of rickets and vitamin D deficiency: new guidelines for vitamin D intake. Pediatrics. 2003; 111(4 Pt 1):908-910.

35. Bodnar LM, Simhan HN, Powers RW, Frank MP, Cooperstein E, Roberts JM. High prevalence of vitamin D insufficiency in black and white pregnant women residing in the northern United States and their neonates. J Nutr. 2007;137(2):447-52.

36. Wegienka G, Kaur H, Sangha R, Cassidy-Bushrow AE. Maternal-cord blood vitamin D correlations vary by maternal levels. J Pregnancy. 2016;2016: 7474192.

37. Harris SS. Vitamin D and African Americans. J Nutr. 2006;136(4):1126-9.

38. Bouillon R. Genetic and racial differences in the vitamin D endocrine system. Endocrinol Metab Clin N Am. 2017;46(4):1119-35.

39. Lisi G, Ribolsi M, Siracusano A, Niolu C. Maternal vitamin D and its role in determining fetal origins of mental health. Curr Pharm Des. 2020;26(21): 2497-509.

40. Chen $L$, Wagner $C L$, Dong $Y$, Wang $X$, Shary JR, Huang $Y$, et al. Effects of maternal vitamin D3 supplementation on offspring epigenetic clock of gestational age at birth: a post-hoc analysis of a randomized controlled trial. Epigenetics. 2020:1-11.

41. Clarke G, Stilling RM, Kennedy PJ, Stanton C, Cryan JF, Dinan TG. Minireview: gut microbiota: the neglected endocrine organ. Mol Endocrinol. 2014;28(8): 1221-38.

\section{Publisher's Note}

Springer Nature remains neutral with regard to jurisdictional claims in published maps and institutional affiliations.

Ready to submit your research? Choose BMC and benefit from:

- fast, convenient online submission

- thorough peer review by experienced researchers in your field

- rapid publication on acceptance

- support for research data, including large and complex data types

- gold Open Access which fosters wider collaboration and increased citations

- maximum visibility for your research: over $100 \mathrm{M}$ website views per year

At $\mathrm{BMC}$, research is always in progress.

Learn more biomedcentral.com/submissions 